Cochrane Database of Systematic Reviews

\title{
Opportunities provision for preventing youth gang involvement for children and young people (7-16) (Review)
}

Fisher H, Montgomery P, Gardner F

Fisher H, Montgomery P, Gardner F.

Opportunities provision for preventing youth gang involvement for children and young people (7-16).

Cochrane Database of Systematic Reviews 2008, Issue 2. Art. No.: CD007002.

DOI: 10.1002/14651858.CD007002.pub2.

www.cochranelibrary.com 
TABLE OF CONTENTS

ABSTRACT

PLAIN LANGUAGE SUMMARY

BACKGROUND

OBJECTIVES

METHODS

RESULTS

Figure 1.

DISCUSSION

AUTHORS' CONCLUSIONS

ACKNOWLEDGEMENTS

REFERENCES

CHARACTERISTICS OF STUDIES

ADDITIONAL TABLES

APPENDICES

WHAT'S NEW

HISTORY

CONTRIBUTIONS OF AUTHORS

DECLARATIONS OF INTEREST

SOURCES OF SUPPORT

NOTES

INDEX TERMS 
[Intervention Review]

\section{Opportunities provision for preventing youth gang involvement for children and young people (7-16)}

Herrick Fisher ${ }^{1}$, Paul Montgomery ${ }^{2}$, Frances Gardner ${ }^{1}$

1The Centre for Evidence-Based Intervention, University of Oxford, Oxford, UK. 2Department of Social Policy and Social Work, University of Oxford, Oxford, UK

Contact: Paul Montgomery, Department of Social Policy and Social Work, University of Oxford, Barnett House, 32 Wellington Square, Oxford, OX12ER, UK. paul.montgomery@spi.ox.ac.uk, paul.montgomery@spi.ox.ac.uk.

Editorial group: Cochrane Developmental, Psychosocial and Learning Problems Group.

Publication status and date: Edited (no change to conclusions), published in Issue 10, 2016.

Citation: Fisher H, Montgomery P, Gardner F. Opportunities provision for preventing youth gang involvement for children and young people (7-16). Cochrane Database of Systematic Reviews 2008, Issue 2. Art. No.: CD007002. DOI: 10.1002/14651858.CD007002.pub2.

Copyright (c) 2016 The Cochrane Collaboration. Published by John Wiley \& Sons, Ltd.

\section{A B S T R A C T}

\section{Background}

Youth gangs have long been studied in the United States and interest elsewhere is increasing. Many studies document a robust and consistent relationship between gang membership and elevated delinquency. One theory of gang involvement, drawing on anomie and strain theories, proposes that the gang provides a means of fulfilling the economic needs of youth excluded from legitimate labour markets. Opportunities provision is a gang prevention strategy based on this theory and the principle that providing youth with educational and employment opportunities may reduce gang involvement. Common techniques within opportunities provision include tutoring, remedial education, job training, and job placement.

\section{Objectives}

To determine the effectiveness of opportunities provision for preventing youth gang involvement for children and young people aged 7 to 16 .

\section{Search methods}

Electronic searches were conducted of the Cochrane Library, MEDLINE, ASSIA, CINAHL, CJA, Dissertations Abstracts, EMBASE, ERIC, IBSS, LILACs, LexisNexis Butterworths, NCJR Service Abstracts Database, PsycINFO, and Sociological Abstracts, to April 2007. Reviewers contacted relevant organisations, individuals and list-servs and searched pertinent websites and reference lists.

\section{Selection criteria}

All randomised controlled trials or quasi-randomised controlled trials of interventions that have opportunities provision as the majority component, delivered to children and youths aged 7 to 16 not involved in a gang, compared to any other or no intervention.

\section{Data collection and analysis}

Searches yielded 2,696 unduplicated citations. 2,676 were excluded based on title and abstract. Two were excluded based on personal communication with study authors. Full-text reports for 18 citations were retrieved. 16 were excluded because they were not evaluations, did not address a gang prevention programme, did not include gang-related outcomes, did not include opportunities provision intervention components, or presented preliminary findings for outcomes reported in another citation. The remaining two reports were at least partially relevant to opportunities provision for gang prevention, but methodological flaws excluded both from analysis.

\section{Main results}

No randomised controlled trials or quasi-randomised controlled trials were identified. 


\section{Authors' conclusions}

No evidence from randomised controlled trials or quasi-randomised controlled trials currently exists regarding the effectiveness of opportunities provision for gang prevention. Only two studies addressed opportunities provision as a gang prevention strategy, a case study and a qualitative study, both of which had such substantial methodological limitations that even speculative conclusions as to the impact of opportunities provision were impossible. Rigorous primary evaluations of gang prevention strategies are crucial to develop this research field, justify funding of existing interventions, and guide future gang prevention programmes and policies.

\section{PLAIN LANGUAGE SUMMARY}

\section{Seeking to prevent gang involvement in young people by providing educational or work opportunities}

Research has shown that youth who join gangs are more likely to be involved in delinquency and crime, particularly serious and violent offences, compared to non-gang youth and non-gang delinquent youth. Opportunities provision is a commonly used gang prevention strategy based on anomie and strain theories and the belief that giving youth educational and employment opportunities, such as tutoring or job training and placement, will reduce gang involvement. This systematic review found no randomised controlled trials or quasi-randomised controlled trials of the effectiveness of opportunities provision for gang prevention. There is an urgent need for rigorous primary evaluations of gang prevention and intervention programmes to justify current programme funding and guide future interventions. 


\section{B A C K G R O U N D}

\section{Description of the condition}

\section{Definition of a youth gang}

There is no unanimously accepted definition for a youth gang, reflecting the reality that there is no universal model of a youth gang. Several characteristics, however, typically distinguish youth gangs from other youth groups or organized crime groups, primarily: participation in criminal activity, typically engaging in a range of criminal offences; and projection of a shared identity, through naming, symbols, colours, or association with physical or economic territory (Huff 1993; Spergel 1993; Spergel 1994; Howell 1998; Esbensen 2000; White 2002; OJJDP 2004; Carlsson 2005). Most definitions of youth gangs refer to these two characteristics in some way, but also often include specific group characteristics or gang organizational structures that vary across regions. Most gang members in the United States and internationally are adolescents with the peak age of recruitment into gangs and increased criminal involvement between eleven and fifteen (Kodluboy 1993; Huff 1998; Hill 2001; OJJDP 2004). Most gang members are also ethnic or racial minorities, predominately Hispanic and black/AfricanAmerican, and the vast majority are male, although the percentage of non-minority gang members and female gang members varies substantially with jurisdiction type and between self-report and law enforcement data (Moore 1998; Moore 1999; Egley 2000; Egley 2006; Snyder 2006). The definition used in this review, based on those from the Eurogang Program of Research and the Office of Juvenile Justice and Delinquency Prevention (OJJDP 2004), is intended to accommodate this diversity of gangs and gang definitions, whilst recognizing their common general attributes. A youth gang is defined as 'any durable, street-oriented youth group whose involvement in illegal activity is part of their group identity' (Esbensen 2005), excluding prison gangs, ideological gangs, hate groups, and motorcycle gangs (Huff 1993; Howell 1998).

\section{Increased delinquency associated with youth gang} membership

Gang members are disproportionately involved in crime, particularly serious and violent offences, compared to nongang youth and non-gang delinquent youth (Thornberry 1997; Battin 1998; Howell 1998; Hill 1999; Hill 2001; OJJDP 2004). This heightened delinquency is consistent when measured by number of offences, rate of committing serious and violent offences, and adjusted frequency of hidden delinquency (Spergel 1994; Howell 1998; Huff 1998; Esbensen 2000; Hill 2001). Research indicates that gang membership has a unique criminogenic influence over and above the effect of having delinquent peers or prior involvement in delinquency (Battin 1998), suggesting that there may be a unique aspect of the gang as a delinquency-enhancing social unit. This, together with the policy concern about the extent of gang crime, suggests that gang prevention and gang outcomes per se warrant independent study.

\section{International prevalence of youth gangs}

Most of the research into youth gangs has been conducted in the United States, where the number of active gangs peaked in the mid-1990s with more than 30,000 gangs and 840,000 gang members nationwide (Moore 1998, Snyder 2006). The most recent data estimate that there are about 24,000 gangs and 760,000 active gang members across the United States (Snyder 2006).
Internationally, gang research has only begun to occur, but street gangs or what are sometimes called 'troublesome youth groups' (Decker 2005) have been identified in developed and developing countries in South America, Europe, Asia, and Africa (Carlsson 2005, Covey 2003, Decker 2005, Klein 2006, Papachristos 2005). Preliminary examinations have concluded that the youth gangs in several of these countries mirror the nature, pattern of emergence, and behaviour of the more extensively studied American street gangs (Klein 1995).

\section{One theory of gang formation: exclusion from the legitimate opportunities system}

There is a wide range of theories regarding why youth become involved in gangs, including those emphasizing individual risk and protective factors or cognitive mechanisms, and others that adopt a more macro approach, drawing on social disorganization, social control, or strain theory. One of these latter theories proposes that the gang provides a means of fulfilling the economic needs of youth excluded from the legitimate labour market. This theory is supported by the finding that "underclass" youth raised in conditions of social deprivation and exclusion are particularly likely to be drawn to gangs and associated delinquency as an alternative means to achieve status and success when the legitimate opportunities system is closed to them (Goldstein 1993; Huff 1993; Howell 1998; Stinchcomb 2002). Additionally, several community-structural factors suggesting limited access to the legitimate labour market are associated with increased probability of gang activity or development: loss of industrial jobs, outmigration of middle-class black people, growing failure of schools to prepare inner-city students to enter the service economy, reduced job opportunities, and lack of social opportunities (Klein 1995; Stinchcomb 2002). Identified risk factors for youth gang involvement also include low academic achievement, educational frustration, living in poverty, and barriers to economic and social opportunities (Howell 1998; Maxson 1998; Hill 1999; OJJDP 2004).

\section{Description of the intervention}

\section{Opportunities provision gang prevention programmes}

Opportunities provision is a gang prevention strategy derived from this theory about why youth become involved in gangs, based on the premise that providing the relevant educational and employment opportunities at various developmental stages will reduce the need or motivation for young people to join gangs (Spergel 1997). Opportunities provision thus encompasses tutoring, supplementary or remedial education, job training and preparation, job development, job placement, and other programmes designed to increase economic or educational opportunities or enable youth to take advantage of them (Goldstein 1993, Spergel 1991, Spergel 1993).

Popular in the 1960 s-70s as an intervention strategy with active gang members, opportunities provision has also been used in programmes designed to prevent youth from joining gangs. The Bay Area Youth Employment Project (BAYE) in northern California is one example of an opportunities provision prevention programme; BAYE offers biweekly career and college workshops to at-risk youth and provides job placements on a university campus (Corsica 1993). Some opportunities provision gang prevention programmes provide other services in addition to job training or placement. For instance, YouthBuild/YAP in New York teaches construction skills, offers paid construction work, provides job placement services, 
and also offers peer counselling and cognitive skills development training (Corsica 1993).

\section{How the intervention might work}

\section{Potential of opportunities provision for gang prevention}

A 1988 survey of the distribution of gang interventions in the United States, conducted by the National Youth Gang Suppression and Intervention Program and Office of Juvenile Justice and Delinquency Prevention (OJJDP 2004), found that social opportunities provision was associated with the highest levels of 'perceived general effectiveness' in cities with chronic gang problems, compared to intervention strategies of suppression, social intervention, organizational change and development, or community organization and mobilization (Spergel 1990, Spergel 1993). The 'perceived general effectiveness' measure was created by the authors for the study, introducing potential bias, however, it was significantly correlated with five empirical indicators of gang activity in a subsequent validity check (Spergel 1993).

Studies also indicate the potential effectiveness of opportunities provision initiatives, such as one 1996 survey of past and current gang members in which $49.1 \%$ of respondents felt that job training and employment programmes were effective in preventing gang membership, $75 \%$ of respondents disagreed with the statement that job training was a waste of time, and employment services was the largest single preference of respondents (39.4\%) for programmes to keep youth out of gangs (Corsica 1993; Houston 1996).

Research on the developmental stages of youth and gang involvement suggest that opportunities provision may have the greatest potential for effectiveness when administered within late childhood and early adolescence, approximately between ages seven and sixteen. This is the period when young people demonstrate decreasing levels of supervision by parents, increasing independence in the community, and increasing salience of peer group influence (Dishion 1999); it is also when youth typically begin involvement in youth gangs and may be most responsive to prevention programmes (OJJDP 2004, Connor 2002, Hill 2001, Huff 1998, Kodluboy 1993).

\section{Why it is important to do this review}

Although narrative summaries of gang prevention programmes have emerged over the past fifteen years, the effectiveness of opportunities provision for preventing youth gang involvement has never been systematically assessed. The proposed review sought to address this important gap in the gang prevention research base, to enable practitioners and policy-makers to develop evidence-based preventive interventions in response to a youth gang presence in their community.

\section{OB JECTIVES}

To assess the effectiveness of opportunities provision programmes for preventing youth gang involvement for children and young people (7-16).

\section{METHODS}

\section{Criteria for considering studies for this review Types of studies}

Studies were eligible for inclusion if allocation to group was by random allocation or quasi-random allocation (for instance, by alphabetical order or by alternating sequence or day of the week).

\section{Types of participants}

Children and young people aged 7-16 who were not involved in a gang.

\section{Types of interventions}

Opportunities provision, as defined in Background.

Programmes combining opportunities provision with other interventions, such as recreational or cognitive-behavioural interventions, would have been included only if opportunities provision was the majority intervention i.e. more than $50 \%$ of total programming, based on frequency and duration as determined independently by two reviewers (HF and PM). Study authors would have been contacted for more information if there had been any discrepancy between the two review authors or if either had estimated that the proportion of alternative interventions was between $40 \%$ and $60 \%$.

Multi-intervention programmes that included opportunities provision but have a cognitive-behavioural intervention as the majority intervention would have been excluded from this review and considered for inclusion in a separate review (Cognitivebehavioural interventions for preventing youth gang involvement for children and young people (7-16) (Fisher 2008)).

Studies with any other intervention as the majority component were excluded.

The primary control comparison for opportunities provision was no intervention. Comparisons against other interventions, specifically designed for gang or delinquency prevention or other social services or support interventions being delivered to the control group, were included but would have been discussed separately.

\section{Types of outcome measures}

\section{Primary outcomes}

1) Gang membership status (dichotomous); and

2) Gang-related delinquent behaviour and criminal offences, including homicide, assault, robbery, burglary, and drug trafficking (objective measures such as arrest and subjective measures such as self-report were acceptable).

\section{Secondary outcomes}

1) Employment status for youth sixteen and older at outcome measurement;

2) School-reported truancy;

3) Achievement of scholastic benchmarks for youth eighteen and under at outcome measurement;

4) Delinquent behaviour and criminal offences external to gang activities or committed by an individual not involved in a gang;

5) Association with delinquent peers (measured through a peer delinquency scale, as a dichotomous variable, as a percentage of 
time spent with delinquent peers, or as a percentage of friends who are identified as delinquent);

6) Objective and subjective measures of illegal drug abuse;

7) Hospitalisation or injury due to a) gang-related activities, or

b) delinquent activities, as determined by self-report or hospital record; and

8) Firearm possession (both conviction and self-report).

Instruments used to measure these outcomes could have included self-report or official records, such as school, police, probation, or court data. When applicable, self- and other-reported outcome measures would have been analysed separately due to possible divergence, but would not have been ranked in terms of reliability (Dishion 2005).

When available, behavioural and attitudinal measures of problem behaviour and related constructs, such as those in the National Evaluation of GREAT Student Questionnaire (Esbensen 1999), would have been included.

Outcomes had to be reported in quantitative terms and include end point (post-intervention) data for both experimental and control groups.

\section{Outcome intervals}

Outcomes would have been measured post-intervention, after a short-term follow-up period up to 6 months, after a medium-term follow-up period up to 18 months, and after a long-term follow-up period up to 5 years, as data were available, to assess the durability of the intervention.

\section{Search methods for identification of studies}

A three-part search strategy was undertaken to maximise chances of capturing all relevant literature.

\section{Electronic searches}

Databases were searched for published and unpublished studies. No language restrictions were imposed on any results from any search attempts, although most databases were searched in English. No filters based on methodology were applied because test searches indicated that such filters might eliminate relevant studies. A highly sensitive search strategy (a search that was likely to capture all relevant reports) was used rather than a more specific one (a search that would have identified fewer irrelevant papers).

The following databases were searched electronically:

The Cochrane Library (Issue 2, 2007)

MEDLINE (1950 to April Week 32007$)$

ASSIA (1987 to April 2007)

CINAHL (1982 to April Week 4 2007)

Criminal Justice Abstracts (1968 to November 2007)

Dissertation Abstracts (1861 to April 2007)

EMBASE (1980 to 2007 Week 17)

ERIC (1966 to May 2007)

International Bibliography of Social Sciences (IBSS)(1951 to April

Week 04 2007)

LexisNexis Butterworth Services (up to April 2007)

LILACS (up to April 2007)

National Criminal Justice Reference Service (up to October 2007)

PsycINFO (1806 to April Week 12007 )

Sociological Abstracts (Earliest to 2007)
The search strategies used for the databases listed above can be found in Appendix 1, Appendix 2, Appendix 3, Appendix 4, Appendix 5, Appendix 6, Appendix 7, Appendix 8, Appendix 9, Appendix 10, Appendix 11, Appendix 12, Appendix 13, and Appendix 14.

\section{Searching other resources}

\section{Personal communications}

Appropriate government departments, non-governmental organisations, non-profit groups, advocacy groups, user groups, and experts in the field were contacted. Additionally, delinquency prevention and gang oriented email lists (list-servs) were sent a letter requesting assistance in locating studies.

The primary reviewer contacted authors of all included and excluded studies to request details of ongoing and unpublished studies.

\section{Hand searching}

Relevant websites, including those maintained by users, governments, other agencies, and academics and reference lists from previous reviews and all excluded studies were searched by the primary reviewer.

\section{Data collection and analysis}

As no studies met inclusion criteria, all methods planned in the protocol and archived for future updates can be found in additional Table 1.

\section{RES U L T S}

\section{Description of studies}

\section{Results of the search}

The search strategy generated 2,696 unduplicated citations. HF and PM checked titles and abstracts for relevance and excluded 2,676 citations as clearly irrelevant. Two citations appeared potentially relevant but personal communication with study authors indicated that both were excluded from analysis; one did not measure outcomes on an individual level and one did not address a gang prevention programme with opportunities provision components. The remaining 18 citations, which one or both reviewers felt might be relevant, were retrieved in full-text.

Both reviewers examined these full-text articles to determine eligibility and excluded 16 as clearly irrelevant, because: they were descriptions of programs or narrative reviews without evaluations $(n=5)$; did not address a gang prevention programme $(n=5)$; did not include gang-related outcomes $(n=4)$; did not address a gang prevention program with opportunities provision components $(n=1)$; or presented preliminary findings for outcomes reported in another citation $(n=1)$. The remaining two articles were assessed for inclusion criteria, but neither qualified as a randomised or quasirandomised study and therefore both were excluded from analysis. Their methodology and findings are presented in the Excluded Studies table and discussed in Description of Studies.

\section{Included studies}

There were zero included studies.

There were no disagreements between reviewers regarding study inclusion or exclusion. However, study authors would have 
been contacted if further information could have resolved initial disagreements about inclusion and the Review Group Coordinator of the CDPLPG would have been consulted if consensus could not have been reached.
A flowchart of the process of trial selection was made in accordance with the QUORUM statement (Moher 1999) (See also Figure 1).

Figure 1. Study flow diagram

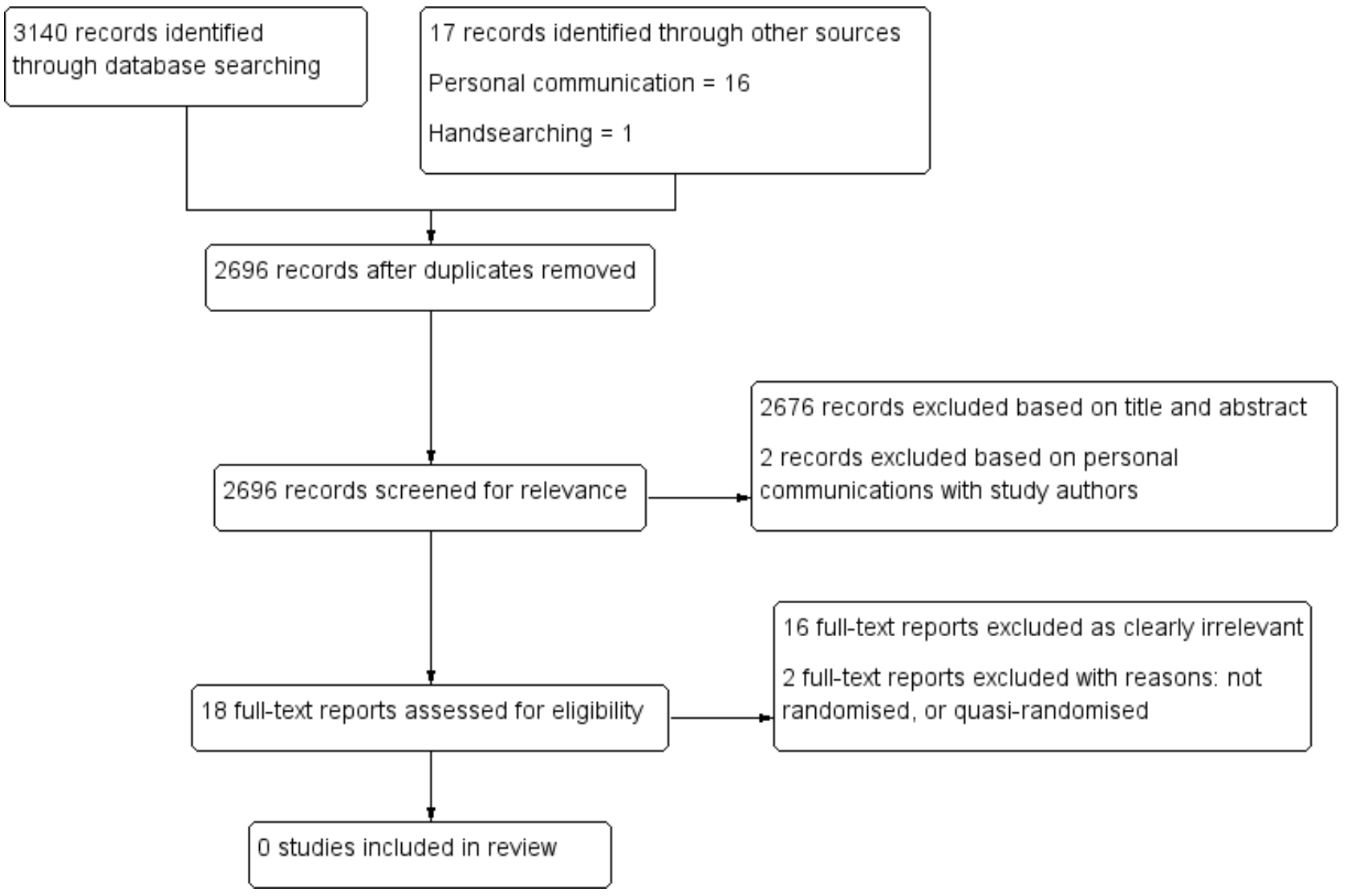

\section{Excluded studies}

Two studies were identified that addressed a gang prevention programme with opportunities provision components (Simun 1996; Weisfeld 1982), but both were excluded (see Table of Excluded Studies). One (Simun 1996) was a case study of a comprehensive gang and drug prevention program for high-risk students in which opportunities provision (tutoring and mentoring in computer labs) was one out of nine different intervention strategies. It was excluded from analysis primarily because there was no comparison group, which made randomisation to condition impossible and prevented assessment of potential effects on outcome measures from factors other than the intervention, such as sample maturation or changing crime levels in the community. Additionally, opportunities provision was not the majority intervention, based on intensity and duration. The other study (Weisfeld 1982) was a qualitative study reporting an interview with one participant - a previous street gang leader who had become a moderately successful business man. As a qualitative study, it automatically was excluded from analysis. It also had several methodological limitations that severely restrict its reliability and validity: there was no presentation of data (quotations from the participant) to support the authors' reported results, no discussion of data collection and analysis methods, and no reflexivity regarding the possible impact of the authors' previous relationship with the participant.

\section{Risk of bias in included studies}

No randomised controlled trials or quasi-randomised controlled trials were found that fulfilled the inclusion criteria.

\section{Effects of interventions}

No randomised controlled trials or quasi-randomised controlled trials were found that fulfilled the inclusion criteria.

\section{DISCUSSION}

This review found no evidence from randomised controlled trials or quasi-randomised controlled trials regarding the effectiveness or ineffectiveness of opportunities provision for preventing youth gang involvement. Two excluded studies addressed opportunities provision to some degree: a case study of a multi-component gang prevention programme for high-risk students that included some opportunity provision components and a qualitative study of one interview with an ex-street gang leader. However, these studies had such substantial methodological flaws that they do not support even speculative conclusions as to the possible impact of opportunities provision on deterring gang involvement 
or any secondary outcome measures. The only finding from this systematic review, therefore, is the absence of any rigorous primary research regarding opportunities provision for gang prevention.

\section{AUTHORS' CONCLUSIONS}

\section{Implications for practice}

The complete lack of evidence from randomised controlled trials, quasi-randomised controlled trials, or excluded studies found by this extremely sensitive search of all available literature makes it very difficult to advise practitioners as to future intervention and policy efforts. The only possible conclusion is the urgent need for good quality primary research regarding opportunities provision for gang prevention. Consequently, the only potential recommendation for practitioners is to demand rigorous evaluations of gang prevention programmes that include opportunities provision components, evaluations that can guide future funding and intervention profiles.

\section{Implications for research}

As stated above, the paucity of good quality research regarding gang prevention programmes and specifically gang prevention programmes based on opportunities provision must be addressed. That this review found only two excluded studies with considerable methodological flaws so as to prevent even speculative conclusions is a reflection of this paucity and the insufficient international commitment to delinquent youth, gangs, and good quality social research. This research void must be remedied to ensure responsible funding choices and succeed in reducing youth gang involvement and the associated crime and delinquency. A review looking at the impact of opportunities provision on delinquency more generally would perhaps be of value.

\section{ACKN OWLEDGEMENTS}

Jo Abbott, Trial Search Coordinator of the Cochrane Developmental, Psychosocial and Learning Problems Group, for advice regarding the search strategy. Jennifer Burton, Centre for Evidence-Based Intervention, for editing and formatting. 


\section{RE F E R E N C E S}

\section{References to studies excluded from this review}

Simun 1996 \{published data only\}

* Simun PB, Slovacek SP, Batie M, Simun M. Project Support Evaluation, Los Angeles Unified School District. Report No 3. Final Evaluation. Los Angeles: California State University, 1996.

\section{Weisfeld 1982 \{published data only\}}

* Weisfeld GE, Feldman R. A Former Street Gang Leader Reinterviewed Eight Years Later. Crime and Delinquency 1982;28(4):567-81.

\section{Additional references}

\section{Battin 1998}

Battin SR, Hill KG, Abbott RD, Catalano RF, Hawkins JD. The contribution of gang membership to delinquency beyond delinquent friends. Criminology 1998;36(1):93-116.

\section{Carlsson 2005}

Carlsson Y, Decker SH. Gang and youth violence prevention and Intervention: Contrasting the Experience of the Scandinavian Welfare State with the United States. European Street Gangs and Troublesome Youth Groups. Lanham, MD: Alta Mira, 2005:259-286.

\section{Connor 2002}

Connor DF. Aggression and antisocial behaviour in children and adolescents: Research and treatment. New York: The Guilford Press, 2002.

\section{Corsica 1993}

Corsica JY. Employment training interventions. In: Goldstein AP, Huff CR editor(s). The Gang Intervention Handbook. Champaign, IL: Research Press, 1993.

\section{Counsell 1994}

Counsell C, Clarke M, Slattery J, Sandercock P. The miracle of DICE therapy for acute stroke: fact or fictional product of subgroup analysis?. BMJ Clinical Research 1994;309(6970):1677-1681.

\section{Covey 2003}

Covey HC. Street gangs throughout the world. Springfield, IL: Charles C Thomas, 2003.

\section{Dane 1998}

Dane A, Schneider B. Program integrity in primary and early secondary prevention: Are implementation effects out of control?. Clinical Psychology Review 1998;18:23-45.

\section{Decker 2005}

Decker SC, Weerman FM. European street gangs and troublesome youth groups. Lanham, MD: Alta Mira, 2005.

\section{Deeks 2005}

Deeks J, Macaskill P, Irwig L. The performance of tests of publication bias and other sample size effects in systematic review of diagnostic test accuracy was assessed. Journal of Clinical Epidemiology 2005;58(9):882-893.

\section{Delgado 2004}

Delgado-Rodriguez M, Llorca J. Bias. Journal of Epidemiology and Community Health 2004;58(8):635-641.

\section{Dishion 1999}

Dishion TJ, Capaldi DM, Yoerger K. Middle childhood antecedents to progressions in male adolescent substance use: An ecological analysis of $r$ isk and protection. Journal of Adolescent Research 1999;14(2):175-205.

\section{Dishion 2005}

Dishion TJ, Nelson SE, Yasui M. Predicting early adolescent gang involvement from middle achool adaptation. Journal of Clinical Child and Adolescent Psychology 2005;34(1):62-73.

\section{Egger 1997}

Egger M, Davey Smith G, Schneider M, Minder, C. Bias in metaanalysis detected by a simple, graphical test. BMJ Clinical Research 1997;315(7109):629-634.

\section{Egley 2000}

Egley A Jr. Highlights of the1999 National Youth Gang Survey. Fact Sheet. Washington, DC: US Department of Justice, Office of Juvenile Justice and Delinquency Prevention, 2000.

\section{Egley 2006}

Egley A Jr, Howell JC, Major AK. National Youth Gang Survey 1999-2001. OJJDP Summary. Washington DC: US Department of Justice, Office of Juvenile Justice and Delinquency Prevention, 2006.

\section{Esbensen 1999}

Esbensen F-A, Osgood D. Gang Resistance Education and Training (GREAT): Results from the national evaulation. Journal of Research in Crime and Delinquency 1999;36(2):194-225.

\section{Esbensen 2000}

Esbensen F-A. Preventing adolescent gang involvement. Bulletin. Washington, DC: US Department of Justice, Office of Juvenile Justice and Delinquency Prevention, 2000.

\section{Esbensen 2005}

Esbensen F-A, Weerman FM. Youth gangs and troublesome youth groups in the United States and the Netherlands; a cross-national comparison. European Journal of Criminology 2005;2(1):5-37.

\section{Fisher 2008}

Fisher H, Gardner F, Montgomery P. Cognitive-behavioural interventions for preventing youth gang involvement for children and young people (7-16). Cochrane Database of Systematic Reviews 2008, Issue 2. [DOI: 10.1002/14651858.CD007008.pub2] 


\section{Goldstein 1993}

Goldstein AP. Gang intervention: A historical review. In: Goldstein AP, Huff CR editor(s). The Gang Intervention Handbook. Champaign IL: Research Press, 1993.

\section{Higgins 2002}

Higgins J, Thompson S. Quantifying heterogeneity in a metaanalysis. Statistics in Medicine 2002;21(11):1539-1558.

\section{Higgins 2003}

Higgins J, Thompson S, Deeks J, Altman D. Measuring inconsistency in meta-analyses. BMJ Clinical Research 2003;327(7414):557-560.

\section{Higgins 2005}

Higgins J, Green S. Cochrane handbook for systematic reviews of interventions. The Cochrane library. 3. Chichester, UK: John Wiley \& Sons, Ltd., 2005.

\section{Hill 1999}

Hill KG, Howell JC, Hawkins JD, Battin-Pearson SR. Childhood risk factors for adolescent gang membership: Results from the Seattle Social Development Project. Journal of Research in Crime and Delinquency 1999;36(3):300-322.

\section{Hill 2001}

Hill KG, Lui C, Hawkins JD. Early precursors of gang membership: A study of Seattle youth. Bulletin. December. Washington, DC: US Department of Justice, Office of Juvenile Justice and Delinquency Prevention, 2001:5.

\section{Houston 1996}

Houston J. What works: The search for excellence in gang intervention programs. Journal of Gang Research 1996;3(3):1-16.

\section{Howell 1998}

Howell, JC. Youth Gangs: An Overview. Bulletin. Washington, DC: US Department of Justice, Office of Juvenile Programs, Office of Justice and Delinquency Prevention, 1998.

\section{Huff 1993}

Huff CR. Gangs in the United States. In: Goldstein AP, Huff CR editor(s). The Gang Intervention Handbook. Champaign, IL: Research Press, 1993.

\section{Huff 1998}

Huff CR. Comparing the criminal behaviour of youth gangs and at-risk youths. Research in brief. Washington, DC: US Department of Justice, Office of Justice Programs National Institute of Justice, 1998.

\section{Juni 2001}

Juni P, Altman DG, Egger M. Systematic reviews in health care: Assessing the quality of controlled clinical trials. BMJ Clinical Research 2001;323(7303):42-46.

\section{Klein 1995}

Klien MW. The American street gang: Its nature, prevalence, and control. New York: Oxford University Press, 1995.

\section{Klein 2006}

Egley A Jr, Maxson CL, Miller J, Klein MW. Street gangs: A crossnational perspective. The modern gang reader. Los Angeles, CA: Roxbury Publishing Company, 2006.

\section{Kodluboy 1993}

Kodluboy DW, Evenrud LA. School-based interventions: Best practices and critical issues. In: Goldstein AP, Huff CR editor(s). The Gang Intervention Handbook. Champaign, IL: Research Press, 1993.

\section{Maxson 1998}

Maxson CL, Whitlock ML, Klein MW. Vulnerability to street gang membership: Implications for practice. Social Service Review 1998;March:70-91.

\section{Moher 1995}

Moher D, Jadad AR, Nichol G, Penman M, Tugwell P, Walsh S. Assessing the quality of randomized controlled trials: An annotated bibliography of scales and checklists. Controlled Clinical Trials 1995;16(1):62-73.

\section{Moher 1999}

Moher D, Cook D, Eastwood S, Olkin, I, Rennie D, Stroup D. Improving the quality of reports of meta-analyses of randomised controlled trials: the QUOROM statement. Lancet 1999;354:1896-1900.

\section{Montgomery 2005}

Montgomery P, Gardner F, Operario D, Mayo-Wilson E, Tamayo S, Underhill K. The Oxford Implementation Reporting Index: The development of an indicator of treatment fidelity in systematic review of psycho-social interventions (poster). Melbourne: XIII Cochrane Colloquium, 2005 (October).

\section{Moore 1998}

Moore JP, Terrett CP. Highlights of the 1996 national youth gang survey. Fact Sheet. Washington, DC: US Department of Justice, Office of Justice Programs, Office of Juvenile Justice and Delinquency Prevention, 1998.

\section{Moore 1999}

Moore JP, Cook IL. Highlights of the 1998 National Youth Gang Survey. Fact Sheet. Washington, DC: US Department of Justice, Office of Juvenile Justice and Delinquency Prevention, 1999.

\section{MRC 2000}

MRC. A framework for development and evaluation of RCTs for complex interventions to improve health. London: Medical Research Council, 2000.

\section{OJJDP 2004}

OJJDP. Gang Prevention. Model Programs Guide Version 2.5 2004.

\section{Oxman 1992}

Oxman A, Guyatt G. A consumer's guide to sub-group analyses. Annals of Internal Medicine 1992;116(1):78-84. 


\section{Papachristos 2005}

Papachristos AW. Gang World. Foreign policy 2005;147(Mar/ Apr):48-55.

\section{Snyder 2006}

Snyder HN, Sickmund M. Juvenile Offenders and Victims. 2006 National Report. Washington, DC: US Department of Justice, Office of Juvenile Justice and Delinquency Prevention, 2006.

\section{Spergel 1990}

Spergel IA, Curry GD. Strategies and perceived agency Effectiveness in dealing with the youth gang problem. In: Huff CR editor(s). Gangs in America. Newbury Park, CA: Sage Publications Inc, 1980:288-309.

\section{Spergel 1991}

Spergel IA. Youth gangs: Problem and response. Washington, DC: US Department of Justice, Office of Juvenile Justice and Delinquency Prevention, 1991.

\section{Spergel 1993}

Spergel IA, Curry GD. The national youth gang survey: A research and development process. In: Goldstein AP, Huff CR editor(s). The Gang Intervention Handbook. Champaign, IL: Research Press, 1993.

\section{Spergel 1994}

Spergel I, Curry D, Chance R, Kane C, Ross R, Alexander A, Simmons E, Oh S. Gang suppression and intervention: Problem and response. Research Summary. Washington, DC: US Department of Justice, Office of Juvenile Justice and Delinquency Prevention, 1994.

\section{CHARACTERISTICS OF STUDIES}

Characteristics of excluded studies [ordered by study ID]

\section{Spergel 1997}

Spergel IA, Grossman SF. The little village project: A community approach to the gang problem. Social Work 1997;42(5):456-70.

\section{Sterne 2001}

Sterne JA, Egger M. Funnel plots for detecting bias in metaanalysis: guidelines on choice of axis. Journal of Clinical Epidemiology 2001;54(10):1046-1055.

\section{Stinchcomb 2002}

Stinchcomb JB. Promising (and not-so-promising) gang prevention and intervention strategies: A comprehensive literature review. Journal of Gang Research 2002;10(1):27-46.

\section{Thornberry 1997}

Thornberry, TP, Burch JHI. Gang members and delinquent behavior. Bulletin. Washington, DC: US Department of Justice, Office of Justice Programs, Justice and Delinquency Prevention, 1997.

\section{White 2002}

White R. School Strategies to Deal with Gangs; trends \& issues in crime and criminal justice. 6. Canberra: Australian Institute of Crimonolgy, 2002.

\section{Yusuf 1991}

Yusuf S, Wittes J, Probstfield J, Tyroler HA. Analysis and interpretation of treatment effects in subgroups of patients in randomised clinical trials. JAMA 1991;266(1):93-98.

* Indicates the major publication for the study

\begin{tabular}{ll}
\hline Study & Reason for exclusion \\
\hline Simun 1996 & Allocation: Not randomised; no comparison group. \\
& Participants: High-risk students in six Los Angeles, California (USA) schools; ages 9-13. \\
Intervention: Project Support; opportunities provision (tutoring and mentoring in computer labs) \\
was one out of 9 intervention strategies--not the majority intervention component based on inten- \\
sity and duration. \\
Reported results: Small, non-significant gains in all student attitudes after receiving intervention; \\
across the six school, 15\% decrease in crimes against persons, 43.5\% decrease in property crimes. \\
Methodological limitations: No comparison group prevents assessment of potential effects on out- \\
come measures from factors other than the intervention, i.e. sample maturation or changing local \\
crime levels.
\end{tabular}
Intervention: None administered.

Reported results: Participant endorses economic or differential opportunity model of crime causation and believes that many youth attracted to gang and criminal involvement because the advantages of legitimate work are not apparent to them.

Methodological limitations: No presentation of data (quotations; testimony) to support authors' reported results; no discussion of data collection and analysis methods; no reflexivity regarding possible impact of authors' previous relationship with participant. 
ADDITIONAL TABLES

Table 1. Table of methods archived for use in future updates

\begin{tabular}{ll}
\hline Issue & Method \\
\hline Data management & Data extraction \\
& Review authors will independently conduct data extraction using a specially developed data ex- \\
traction form. Where the essential statistics are not presented or further information is required, \\
study authors will be contacted. Relevant information will be included in the description of studies.
\end{tabular}

Data collection

When more than two treatment arms were included in the same trial, all arms will be described. The following data will be collected for all trial arms:

1) Descriptive data, including participant demographics (age, gender, ethnicity, familial gang involvement, previous criminal record);

2) Intervention characteristics (including delivery, duration, setting, within-intervention variability, and programme staff demographics);

3) Other services received; and

4) Outcome measures listed above.

The following data will be collected for all studies:

1) Programme differentiation, such as contact or crossover between groups, modifications of procedures, use of intervention curricula or protocols, and actual frequency and duration of administered and received interventions (Dane 1998, Montgomery 2005, MRC 2000); and

2) Context.

Methodological quality

Both reviewers will independently assign each included study to a quality category described in the Cochrane Handbook (Higgins 2005). Study authors will be contacted if further information could resolve initial disagreements about quality categories and if a consensus cannot be reached, the Review Group Coordinator of the CDPLPG will be consulted. Criteria to determine quality categories: A) indicated adequate concealment of the allocation (for example, by telephone randomisation, or use of consecutively numbered, sealed, opaque envelopes);

(B) indicated uncertainty about whether the allocation was adequately concealed (for example, where the method of concealment is not known);

(C) indicated that the allocation was definitely not adequately concealed (for example, open random number lists or quasi-randomisation such as alternate days, odd/even date of birth, or hospital number)

In studies classified as ' $\mathrm{B}$ ' (unclear) and ' $\mathrm{C}$ ' (inadequate) the pre-treatment assessment and the allocation of participants will be described in the Description of Studies to identify differences between intervention and control groups that may have existed at baseline.

Existing scales for measuring the quality of controlled trials have not been properly developed, are not well-validated and are known to give differing (even opposing) ratings of trial quality in systematic reviews (Moher 1995). At present, evidence indicates that, "scales should generally not be used to identify trials of apparent low quality or high quality in a given systematic review. Rather, the relevant methodological aspects should be identified a priori and assessed individually" (Juni 2001).

The following components would have been described in narrative form in the Description of studies:

1) Allocation bias (Was group assignment related to outcomes or the interventions received? Attention would have been given to the possible impact of allocation methods on the magnitude and direction of results);

2) Performance bias (Were there systematic differences in care given to the treatment and control groups other than the intervention in question; could the services provided have been influenced by something other than the interventions being compared?);

3) Detection bias (Were outcomes influenced by anything other than the constructs of interest, including biased assessment or the influence of exposure on detection?); 
Table 1. Table of methods archived for use in future updates (Continued)

4) Report bias (Were the outcomes, measures and analyses selected a priori and reported completely? Were participants biased in their recall or response?);

5) Attrition bias (Could deviations from protocol, including missing data and dropout, have influenced the results?) (Delgado 2004, Juni 2001); and

6) Outcome validity (Were the outcome measures objective, validated for the population, reported directly by the user or obtained through official records, etc.?).

Multiple measures

When a single study provides multiple measures of the same outcome, we will report all measures. For example, if a study includes two measures of quality of life (either measures completed by the same respondent or measures completed by different respondents), we will report both of them. If measures of an outcome are combined for meta-analysis, we will conduct multiple meta-analyses if multiple studies report multiple measures that can be combined in this way. If we conduct metaanalyses in which only one effect estimate can be used from each study, we will select one measure if it is more valid or reliable than the others. For example, if a single respondent completes both a validated scale assessing multiple domains of quality of life and an unvalidated visual analogue scale, we will select the validated scale. If a study includes several equally valid measures and only one effect estimate can be used for meta-analysis, we will calculate the average effect for this purpose (e.g. the average SMD or RR weighted by variance).

Multiple arms

If two or more eligible intervention groups are compared to an eligible control, thus requiring that the reviewers choose a single intervention group for comparison or inclusion in a meta-analysis, the most intense service or the service that best follows the goals of personal assistance (e.g., services that give users more control) will be included in the meta-analysis. If a single eligible intervention group is compared to multiple eligible control groups, 'no-treatment' controls will be chosen over other groups for comparison and inclusion in meta-analyses. For studies that do not have notreatment condition, the most common intervention in clinical practice will be chosen to maximise the external validity of the results.

Data synthesis

(Outcome data)

Continuous data

Dichotomous data

Meta-analyses may be conducted to combine comparable outcome measures across studies. All overall effects will be calculated using inverse variance methods. Random-effects models will be used because studies may include somewhat different treatments or populations.

Mean differences, standardised mean differences (SMDs) and 95\% Cls will be calculated for comparisons of continuous outcome measures.

Within studies, relative risks (RRs) and 95\% confidence intervals (Cls) will be calculated for comparisons of dichotomous outcome measures. Dichotomous outcome measures may be combined by calculating an overall RR and $95 \% \mathrm{Cl}$.

Continuous outcomes

Continuous outcome measures may be combined when means and standard deviations or complete significance testing statistics are available, unless statistical tests assuming normality would be inappropriate. For example, for scales beginning with a finite number (such as 0 ), effect estimates will not be combined unless a mean is greater than its standard deviation (otherwise the mean would be very unlikely to be an appropriate measure of the centre of the distribution). If continuous outcomes are measured identically across studies, an overall weighted mean difference (WMD) and $95 \% \mathrm{Cl}$ may be calculated. If the same continuous outcome is measured differently across studies, an overall standardised mean difference (SMD) and $95 \% \mathrm{Cl}$ may be calculated (Higgins 2005). SMDs will be calculated using Hedges g.

Types of analyses

Studies in which participants are analysed as members of the groups to which they were originally assigned (intention-to-treat analysis), studies that include only those participants who were willing or able to provide data (available-case analysis), and studies that analyse participants who adhered to the study's design (per-protocol analysis; Higgins 2005) will be analysed separately. Studies in which the reasons for excluding participants from analyses can not be determined from relevant reports or through contact with the authors will be considered with per-protocol analyses.

Homogeneity

The consistency of results will be assessed using the I-squared statistic (Higgins 2002; Higgins 2003). If there is evidence of heterogeneity (Q-statistic $p$ less than or equal to 0.1 coupled with an 12 value of $25 \%$ or greater), the authors will consider sources according to pre-specified subgroup analyses and sensitivity analyses (below) but will not report an overall estimate of effect size. If het-

Opportunities provision for preventing youth gang involvement for children and young people (7-16) (Review) 
Table 1. Table of methods archived for use in future updates (Continued)

erogeneity remains within these subgroups, the review will report the results on a trial-by-trial basis, in a narrative summary.

Subgroup analyses

Large numbers of subgroups may lead to misleading conclusions and are best kept to a minimum (Counsell 1994; Oxman 1992; Yusuf 1991). If possible, this review will include separate effect estimates for the following subgroups:

1) Organisation of services

2) Place of residence

3) Acquisition of impairment

4) Amount of assistance

\section{Assessment of bias}

Sensitivity analyses will investigate the influence of lower quality studies (i.e., those rated $\mathrm{C}$ and D on allocation concealment) on the results of the review. To investigate the possibility of bias, including publication bias, funnel plots will be drawn (Deeks 2005; Egger 1997; Sterne 2001). In the event of asymmetry, the reviewers will seek input from methodologists, including the Cochrane and Campbell Collaboration Methods Groups, on appropriate analyses.

\section{APPENDICES}

\section{Appendix 1. Cochrane Library search strategy}

Cochrane Library searched Issue 2, 2007

The search strategy used for the Cochrane Library (including The Cochrane Database of Systematic Reviews, Database of Abstracts of Reviews of Effects, The Cochrane Central Register of Controlled Trials, The Cochrane Methodology Register, Health Technology Assessment Database, NHS Economic Evaluation Database, and About The Cochrane Collaboration) was as follows:

[(MeSH descriptor Adolescent explode all trees) OR (youth OR adolescen^ OR juvenile OR child OR schoolchild OR boy OR girl OR teen OR (young person*) OR (young people*)):ti,ab,kw]

AND

[(MeSH descriptor Juvenile Delinquency explode all trees) OR (gang OR delinquen* OR devian* OR (anti NEXT social) OR (youth* NEAR group)):ti,ab,kw]

AND

[(MeSH descriptor Remedial Teaching explode all trees) OR (MeSH descriptor Vocational Guidance explode all trees) OR (MeSH descriptor Education, Nonprofessional explode all trees) OR ((opportunity NEAR/3 (provi ${ }^{\star}$ OR enhanc $\left.\left.{ }^{\star}\right)\right)$ OR ((remedial OR supplementary) NEAR/3 (teaching OR education)) OR tutor ${ }^{\star}$ OR (vocational NEAR/3 (training OR therapy OR education)) OR ((job OR work OR occupation*) NEAR/3 (training OR placement)) OR (work NEAR/3 experience) OR (industr* NEAR/3 training) OR (apprenticeship)):ti,ab,kw]

\section{Appendix 2. MEDLINE search strategy}

MEDLINE (1950 to April Week 32007 ) was searched via OVID using the follwing terms:

[(adolescent/ or child/) or (youth\$ or adolescen\$ or juvenile\$ or child\$ or schoolchild\$ or boy\$ or girl\$ or teen\$ or (young person\$) or (young people\$)).tw.]

and

[(juvenile delinquency/) or (gang\$ or (youth\$ adj3 group\$) or delinquen\$ or devian\$ or anti?social).tw.]

and

[(remedial teaching/ or vocational guidance/ or education, professional/ or education, continuing/) or ((opportunit\$ adj3 provi\$) or (opportunit\$ adj3 enhanc\$) or (remedial adj3 teach\$) or (remedial adj3 educat\$) or (supplementary adj3 teach\$) or (supplementary adj3 educat\$) or tutor\$ or (vocational adj3 train\$) or (vocational adj3 therap\$) or (vocational adj3 educat\$) or (job adj3 train\$) or (job adj3 placement $\$$ ) or (work adj3 train\$) or (work adj3 placement\$) or (work adj3 experience\$) or (occupation\$ adj3 train\$) or (occupation $\$$ adj3 placement\$) or (industr\$ adj3 train\$) or apprenticeship\$).tw.]

\section{Appendix 3. ASSIA search strategy}

ASSIA, Applied Social Science Index \& Abstracts (1987 to 2007) was searched via CSA using the following terms: 


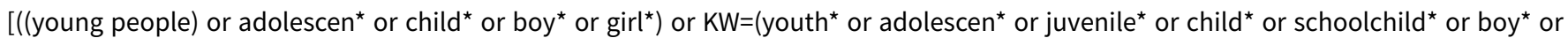
girl $^{\star}$ or teen $\left.\left.{ }^{\star}\right)\right]$

and

$[\mathrm{DE}=$ (delinquen* or devian* or (juvenile crime) or (antisocial behavio* $r$ ) or gangs or (criminal gangs) or (street gangs) or (youth gangs)) or

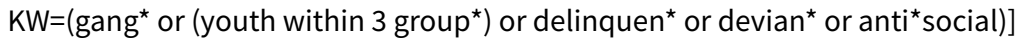

and

$[\mathrm{DE}=(($ vocational training) or (apprenticeships) or (industrial training) or (professional training) or (skills training) or mentoring or

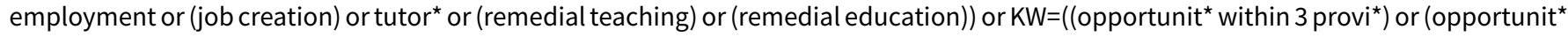
within 3 enhanc $^{\star}$ ) or (remedial within 3 teaching) or (remedial within 3 education) or (supplementary within 3 teaching) or (occupation* within 3 training) or (occupation* within 3 placement) or (industr ${ }^{\star}$ within 3 training) or (supplementary within 3 education) or (tutor ${ }^{\star}$ ) or (vocational within 3 training) or (vocational within 3 therapy) or (vocational within 3 education) or (job within 3 training) or (job within 3 placement) or (work within 3 training) or (work within 3 placement) or (work within 3 experience) or (apprentice $)$ )]

\section{Appendix 4. CINAHL search strategy}

CINAHL, Cumulative Index to Nursing and Allied Health (1982 to April Week 4 2007) was searched via OVID using the following terms:

[(adolescent/ or child/) or (youth\$ or adolescen\$ or juvenile\$ or child\$ or schoolchild\$ or boy\$ or girl\$ or teen\$ or (young person\$) or (young people\$)).tw.]

and

[(juvenile delinquency/ or Gangs/) or (gang\$ or (youth\$ adj3 group\$) or delinquen\$ or devian\$ or anti?social).tw.] and

[((opportunit\$ adj3 provi\$) or (opportunit\$ adj3 enhanc\$) or (remedial adj3 teach\$) or (remedial adj3 educat\$) or (supplementary adj3 teach\$) or (supplementary adj3 educat\$) or tutor\$ or (vocational adj3 train\$) or (vocational adj3 therap\$) or (vocational adj3 educat\$) or (job adj3 train\$) or (job adj3 placement\$) or (work adj3 train\$) or (work adj3 placement\$) or (work adj3 experience\$) or (occupation\$ adj3 train\$) or (occupation\$ adj3 placement\$) or (industr\$ adj3 train\$) or apprenticeship\$).tw. or (Education, Nonprofessional/ or Education, Non-Traditional/ or remedial teaching/ or Vocational Guidance/)]

\section{Appendix 5. Criminal Justice Abstracts search strategy}

CJA, Criminal Justice Abstracts, ( 1968 to November 2007), was searched via CSA using the following terms:

$\left[\left(\mathrm{DE}=\right.\right.$-juvenile) or $\left(\mathrm{KW}=\left(\right.\right.$ youth$^{\star}$ or adolescen ${ }^{\star}$ or juvenile $\left.{ }^{\star}\right)$ or $\mathrm{KW}=\left(\right.$ child $^{\star}$ or schoolchild ${ }^{\star}$ or boy $\left.{ }^{\star}\right)$ or (girl* or teen ${ }^{\star}$ or young person* or $^{*}$ young people*))]

and

$\left[(\mathrm{DE}=(\right.$ juvenile delinquency $))$ or $\left(\mathrm{KW}=\left(\right.\right.$ gang $^{\star}$ or $\left(\right.$ youth* within 3 group $\left.\left.\left.{ }^{\star}\right)\right)\right)$ or $\left(\mathrm{KW}=\left(\right.\right.$ delinquen ${ }^{\star}$ or devian* or anti*social $\left.\left.)\right)\right]$ and

$\left[(\mathrm{DE}=(\right.$ vocational training $))$ or $\left(\mathrm{KW}=\left(\left(\right.\right.\right.$ opportunit $^{\star}$ within 3 provi $\left.^{\star}\right)$ or $\left(\right.$ opportunit ${ }^{\star}$ within 3 enhanc $\left.\left.\left.{ }^{\star}\right)\right)\right)$ or $\left(K W=\left(\left(\right.\right.\right.$ remedial within 3 teach $\left.{ }^{\star}\right)$ or (remedial within 3 educat $\left.^{\star}\right)$ or (supplementary within 3 teach $\left.\left.{ }^{\star}\right)\right)$ or KW $=\left(\left(\right.\right.$ supplementary within 3 educat $\left.{ }^{\star}\right)$ or tutor $\left.\left.{ }^{\star}\right)\right)$ or $\left(\left(\right.\right.$ vocational within $^{\star}$ 3 train $\left.^{\star}\right)$ or (vocational within 3 therap ${ }^{\star}$ ) or (vocational within 3 educat ${ }^{\star}$ ) or (job within 3 train ${ }^{\star}$ ) or (job within 3 placement ${ }^{\star}$ ) or (work within 3 train $^{\star}$ ) or (work within 3 placement ${ }^{\star}$ ) or (work within 3 experience ${ }^{\star}$ ) or (occupation* within 3 train ${ }^{\star}$ ) or (occupation* within 3 placement ${ }^{\star}$ ) or (industr* within 3 train $\left.^{\star}\right)$ or (apprenticeship $\left.\left.{ }^{\star}\right)\right)$ )

\section{Appendix 6. Dissertation Abstracts search strategy}

Dissertation Abstracts International A: The Humanities and Social Sciences, (1861 to April 2007), was searched using the following terms:

[youth? or adolescen? or juvenile? or child? or schoolchild? or boy? or girl? or teen? or (young person?) or (young people?)] and

[delinquen? or devian? or anti-social or antisocial or gang? or (youth? W/15 group?)]

and

[(opportunit? W/15 enhanc?) or (opportunit? W/15 provi?) or (remedial W/15 teach?) or (remedial W/15 education) or (supplementary W/15 teach?) or (occupation? W/15 training) or (occupation? W/15 placement) OR (industr? W/15 training) or (supplementary W/15 education) OR (tutor?) OR (vocational W/15 training) or (vocational W/15 therapy) OR (vocational W/15 education) OR (job W/15 training) OR (job W/15 placement) OR (work W/15 training) OR (work W/15 placement) OR (apprenticeship?) or SU(Education, Early Childhood) or SU(Education, Industrial) or SU(Education, Special) or SU(Education, Vocational)]

\section{Appendix 7. EMBASE search strategy}

EMBASE, (1980 to 2007 Week 17), was searched via OVID using the following terms:

[adolescent/ or juvenile/ or child/ or boy/or girl/ or preschool child/ or school child/ or adolescence/ or childhood/ or (youth\$ or adolescen \$ or juvenile\$ or child\$ or schoolchild\$ or boy\$ or girl\$ or teen\$ or (young person\$) or (young people\$)).tw.] 
and

[delinquency/ or gang/ or juvenile delinquency/ or Antisocial Behavior/ or (gang\$ or (youth\$ adj3 group\$) or delinquen\$ or devian\$ or anti?social).tw.]

and

[job finding/ or vocational education/ or vocational guidance/ or job experience/ or special education/ or remedial teaching/ or vocational guidance/ or education, professional/ or education, continuing/ or ((opportunit $\$$ adj3 provi\$) or (opportunit\$ adj3 enhanc\$) or (remedial adj3 teach\$) or (remedial adj3 educat\$) or (supplementary adj3 teach\$) or (supplementary adj3 educat\$) or tutor\$ or (vocational adj3 train \$) or (vocational adj3 therap\$) or (vocational adj3 educat\$) or (job adj3 train\$) or (job adj3 placement\$) or (work adj3 train\$) or (work adj3 placement\$) or (work adj3 experience\$) or (occupation\$ adj3 train\$) or (occupation\$ adj3 placement\$) or (industr\$ adj3 train\$) or apprenticeship\$).tw.]

\section{Appendix 8. ERIC search strategy}

ERIC, Educational Resources Information Center ( 1966 to May 2007) was searched via CSA using the following terms:

$\left[\mathrm{DE}=\left(\right.\right.$ youth $^{\star}$ or adolescen* or child* or (young adult*) or preadolescen* or (late adolescen $\left.{ }^{\star}\right)$ ) or KW=(youth* or adolescen* or juvenile* or child $^{\star}$ or schoolchild* or boy* or girl* or teen* or (young person*) or (young people*))]

and

[DE=(delinqueny or (juvenile gangs)) or KW=(gang* or (youth within 3 group*) or delinquen* or devian* or anti*social)]

and

$[\mathrm{DE}=(($ career centers) or (employment services) or (employment opportunities) or (employment programs) or (job placement) or (job development) or (job skills) or (job training) or (youth opportunities) or (youth employment) or (vocational education) or (vocational training centers) or (apprenticeships) or (educational opportunities) or (occupational training) or (special education) or (experiential learning)) or $\mathrm{KW}=\left(\left(\right.\right.$ opportunit ${ }^{\star}$ within 3 provi $\left.^{\star}\right)$ or (opportunit* within 3 enhanc $^{\star}$ ) or (remedial within 3 teaching) or (remedial within 3 education) or (supplementary within 3 teaching) or (occupation ${ }^{\star}$ within 3 training) or (occupation ${ }^{\star}$ within 3 placement) or (industr ${ }^{\star}$ within 3 training) or (supplementary within 3 education) or (tutor ${ }^{\star}$ ) or (vocational within 3 training) or (vocational within 3 therapy) or (vocational within 3 education) or (job within 3 training) or (job within 3 placement) or (work within 3 training) or (work within 3 placement) or (work within 3 experience) or (apprentice*))]

\section{Appendix 9. IBSS search strategy}

IBSS, International Bibliography of the Social Sciences, (1951 to April Week 04 2007), was searched via OVID using the following terms:

[(youth or adolescents or adolescence or children).sh. or (youth\$ or adolescen\$ or juvenile\$ or child\$ or schoolchild\$ or boy\$ or girl\$ or teen\$ or (young person\$) or (young people\$)).tw.]

and

[juvenile delinquency.sh. or gangs.sh. or (gang\$ or (youth\$ adj3 group\$) or delinquen\$ or devian\$ or anti?social).tw.]

and

[(education or (vocational education) or (vocational training) or (job placement) or (job search) or (job seekers) or (work experience) or (special education) or (apprenticeship) or (youth training scheme) or (youth employment)).sh. or ((opportunit\$ adj3 provi\$) or (opportunit $\$$ adj3 enhanc\$) or (remedial adj3 teach\$) or (remedial adj3 educat\$) or (supplementary adj3 teach\$) or (supplementary adj3 educat\$) or tutor $\$$ or (vocational adj3 train\$) or (vocational adj3 therap\$) or (vocational adj3 educat\$) or (job adj3 train\$) or (job adj3 placement\$) or (work adj3 train\$) or (work adj3 placement\$) or (work adj3 experience\$) or (occupation\$ adj3 train\$) or (occupation\$ adj3 placement\$) or (industr\$ adj3 train\$) or apprenticeship\$).tw.]

\section{Appendix 10. LexisNexis search strategy}

LexisNexis Butterworths Services, all subscribed journals, (searched up to April 2007), was searched using the following terms:

[(youth or adolescen! or juvenile or child! or schoolchild! or boy or girl or teen! or (young person!) or (young people!))] and

[(gang! or (youth w/3 group) or delinquen! or devian! or antisocial or anti*social)]

and

[((opportunit! w/3 provi! or enhanc!) or (remedial w/3 teaching or education) or (supplementary w/3 teaching or education) or (tutor!) or (vocational w/3 training or therapy or education) or (job w/3 training or placement or service) or (work w/3 training or placement or experience) or (occupation! w/3 training or placement) or (industr! w/3 training) or apprentice!)]

\section{Appendix 11. LILACS search strategy}

LILACs, Latin American and Caribbean Health Services Literature, (searched up to April 2007), was searched via VHL using the following terms:

[youth\$ or adolescen\$ or juvenile\$ or child\$ or schoolchild\$ or boy\$ or girl\$ or teen\$ or (young person\$) or (young people\$) [Palavras] or "adolescent" or "child" [Descritor de assunto]] 
and

[gang\$ or (youth\$ adj3 group\$) or delinquen\$ or devian\$ or anti?social [Palavras] or "juvenile delinquency" [Descritor de assunto] and

[(opportunit\$ adj3 provi\$) or (opportunit\$ adj3 enhanc\$) or (remedial adj3 teach\$) or (remedial adj3 educat\$) or (supplementary adj3 teach\$) or (supplementary adj3 educat\$) or tutor\$ or (vocational adj3 train\$) or (vocational adj3 therap\$) or (vocational adj3 educat\$) or (job adj3 train\$) or (job adj3 placement\$) or (work adj3 train\$) or (work adj3 placement\$) or (work adj3 experience\$) or (occupation\$ adj3 train\$) or (occupation\$ adj3 placement\$) or (industr\$ adj3 train\$) or apprenticeship\$ [Palavras] or "remedial teaching" or "vocational guidance" or "education, professional" or "education, continuing" [Descritor de assunto]]

\section{Appendix 12. NCJRS search strategy}

National Criminal Justice Reference Service Abstracts Database, (searched up to October 2007), was searched using the following terms:

[(youth* OR adolescen* OR juvenile* or child* OR schoolchild* OR boy ${ }^{\star}$ OR girl OR teen ${ }^{\star}$ OR (young people*) OR (young person*))] AND

[(gang* OR delinquen* OR devian* OR anti*social OR (youth group* within 3))]

AND

[((opportunit* (provi $^{\star}$ OR enhanc $\left.{ }^{\star}\right)$ within 3) OR ((remedial OR supplementary) (teach* OR educat $\left.{ }^{\star}\right)$ within 3) OR (vocational (train* OR therap OR educat $\left.^{\star}\right)$ within 3) OR ((job OR work OR occupation*) (train* OR placement*) within 3) OR (tutor ${ }^{\star}$ ) OR (apprenticeship*) OR (industr* train* within 3))]

\section{Appendix 13. PsycINFO search strategy}

PsycINFO, (1806 to April Week 12007$)$, was searched via OVID using the following terms:

[(youth\$ or adolescen\$ or juvenile\$ or child\$ or schoolchild\$ or boy\$ or girl\$ or teen\$ or (young person\$) or (young people\$)).tw.] and

[(juvenile delinquency/ or juvenile gangs/ or antisocial behavior/ or predelinquent youth/) or (gang\$ or (youth\$ adj3 group\$) or delinquen \$or devian\$ or anti?social).tw.]

and

[(occupational guidance/ or mentor/ or vocational education/ or school to work transition/ or nontraditional education/ or remedial education/ or special education/) or ((opportunit\$ adj3 provi\$) or (opportunit\$ adj3 enhanc\$) or (remedial adj3 teach\$) or (remedial adj3 educat\$) or (supplementary adj3 teach\$) or (supplementary adj3 educat\$) or tutor\$ or (vocational adj3 train\$) or (vocational adj3 therap $\$$ ) or (vocational adj3 educat\$) or (job adj3 train\$) or (job adj3 placement\$) or (work adj3 train\$) or (work adj3 placement\$) or (work adj3 experience\$) or (occupation $\$$ adj3 train\$) or (occupation\$ adj3 placement\$) or (industr\$ adj3 train\$) or apprenticeship\$).tw.]

\section{Appendix 14. Sociological Abstracts search strategy}

Sociological Abstracts, (1963 to 2007), was searched via CSA using the following terms:

$\left[\mathrm{DE}=\left(\right.\right.$ youth $^{\star}$ or adolescen ${ }^{\star}$ or child ${ }^{\star}$ or $\left(\right.$ young adult $\left.\left.{ }^{\star}\right)\right)$ or $\mathrm{KW}=\left(\right.$ youth $^{\star}$ or adolescen ${ }^{\star}$ or juvenile or child $^{\star}$ or schoolchild ${ }^{\star}$ or boy ${ }^{\star}$ or girl ${ }^{\star}$ or teen ${ }^{\star}$ or (young person ${ }^{\star}$ ) or (young people $\left.{ }^{\star}\right)$ )]

and

$\left[\mathrm{DE}=\right.$ (gangs or (juvenile offenders) or (juvenile delinqueny)) or $\mathrm{KW}=\left(\right.$ gang* or (youth within 3 group ${ }^{\star}$ ) or delinquen* or devian ${ }^{\star}$ or anti*social)]

and

$[\mathrm{DE}=(($ job training) or (professional training) or (vocational education) or (special education) or (employability) or (work experience) or (work skills) or (occupational qualifications) or (youth employment)) or $\mathrm{KW}=\left(\left(\right.\right.$ opportunit* within 3 provi $\left.^{\star}\right)$ or (opportunit* within 3 enhanc $^{\star}$ ) or (remedial within 3 teaching) or (remedial within 3 education) or (supplementary within 3 teaching) or (occupation* within 3 training) or (occupation* within 3 placement) or (industr* within 3 training) or (supplementary within 3 education) or (tutor ${ }^{\star}$ ) or (vocational within 3 training) or (vocational within 3 therapy) or (vocational within 3 education) or (job within 3 training) or (job within 3 placement) or (work within 3 training) or (work within 3 placement) or (work within 3 experience) or (apprentice*))]

\section{WHAT'S NEW}

Date Event Description

24 October $2016 \quad$ Amended We have replaced Figure 1 with an image of higher quality.




\section{H IS T O R Y}

Protocol first published: Issue 1, 2007

Review first published: Issue 2, 2008

\begin{tabular}{lll}
\hline Date & Event & Description \\
\hline 17 September 2008 & Amended & Converted to new review format. \\
\hline 20 February 2008 & $\begin{array}{l}\text { New citation required and conclusions } \\
\text { have changed }\end{array}$ & Substantive amendment \\
\hline
\end{tabular}

\section{CONTRIBUTIONS OF AUTHORS}

Herrick Fisher: original idea, protocol, searching, trial selection, writing report.

Paul Montgomery: protocol design, data management and data synthesis, editing.

Frances Gardner: protocol design, trial selection, editing

\section{DECLARATIONS OF INTEREST}

This review was supported by the Nordic Campbell Center. The review authors have no known conflicts of interest.

\section{SOURCES OF SUPPORT}

\section{Internal sources}

- Centre for Evidence Based Intervention, University of Oxford., UK.

\section{External sources}

- The Nordic Campbell Center, Denmark.

\section{NOTES}

This review is co-registered within the Campbell Collaboration.

\section{INDEX TERMS}

\section{Medical Subject Headings (MeSH)}

*Peer Group; Crime [ ${ }^{*}$ prevention \& control]; Juvenile Delinquency [ ${ }^{*}$ prevention \& control]; Social Alienation; Social Identification; Vocational Education

\section{MeSH check words}

Adolescent; Child; Humans 